\title{
Validation and Assessment of COVID-19 Peritraumatic Distress Index among Indian Dental Professionals
}

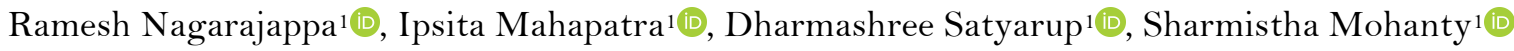

\begin{abstract}
'Department of Public Health Dentistry, Institute of Dental Sciences, Siksha 'O’ Anusandhan (Deemed to be University), Bhubaneswar, Odisha, India.
\end{abstract}

Correspondence: Dr. Ipsita Mahapatra, Department of Public Health Dentistry, Institute of Dental Sciences, Siksha 'O' Anusandhan (Deemed to be University), Bhubaneswar, 751003, Odisha, India. E-mail: dr.ipshita@gmail.com

Academic Editor: Myroslav Goncharuk-Khomyn

Received: 23 January 2021 / Review: 05 March 2021 / Accepted: 21 March 2021

How to cite: Nagarajappa R, Mahapatra I, Satyarup D, Mohanty S. Validation and assessment of COVID-19 Peritraumatic Distress Index among Indian dental professionals. Pesqui Bras Odontopediatria Clín Integr. 2021; $21:$ e0009. https://doi.org/10.1590/pboci.2021.112

\begin{abstract}
Objective: To establish the validity of COVID-19 Peritraumatic Distress Index (CPDI) questionnaire and assess the stress with its associated factors during COVID-19 among dental professionals in Bhubaneswar, India. Material and Methods: An online survey through Google Forms was steered among 234 dentists. CPDI questionnaire was used for data collection post its validation assessment. Content validity was judged satisfactory by two psychiatrists, and excellent internal consistency was found (Cronbach's alpha $=0.92$ ). For statistical analysis, chi-square and binomial logistic regression tests were used with a significance level of $\mathrm{p} \leq 0.05$. Results: $70(29.9 \%)$ were males and $164(70.1 \%)$ were females with a mean age of $30.58 \pm 6.70$ years. Around $50 \%$ had an MDS degree and were attached to an institution and nearly $80 \%$ were having experience of less than 10 years. The mean CPDI score was found to be $29.09 \pm 15.47$. A statistically significant association was observed between CPDI scores with age $(\mathrm{p}<0.003)$, gender $(\mathrm{p}<0.03)$, practice $(\mathrm{p}<0.06)$ and education $(\mathrm{p}<0.006)$. Binomial logistic regression revealed that odds of stress were 2 times higher among males than females $(\mathrm{OR}=2.01, \mathrm{p}<0.04)$, which was statistically significant. Conclusion: Acceptable validation scores confirmed CPDI as an effective instrument for detecting stress. Importance of early interventions to combat the issue of stress among dental professionals as it is allied with negative consequences on health and furthermore affects daily activities is highlighted.
\end{abstract}

Keywords: Pandemics; Coronavirus Infections; SARS-CoV-2; Health Personnel; Dentists. 


\section{Introduction}

The COVID-19 virus (Coronavirus) disease became a public health emergency after its first outbreak in December 2019 in Wuhan city, China. Eventually, on 30th January, 2020, it was declared as a pandemic by the World Health Organization [1]. In India, out of 10,206,901 total confirmed cases, there have been 147,907 registered deaths [2]. This outbreak has affected the health sector and led to many economic, professional, and social barriers for the nation as a whole. Dentistry is one of those professions where there is a risk of constant exposure to COVID-19 virus. The probability of transmission of the virus from person to person during a dental practice is high as the virus can spread through small droplets from the nose or mouth [3]. Other possible transmission routes include airborne spread via aerosols formed during a dental procedure or through contact from contaminated surfaces [4]. Dentists should therefore be responsible for preventing as much transmission of microorganisms as possible.

The Dental Council of India (DCI) issued guidelines for dental clinic after the unlock of the "lockdown period" in India. According to the guidelines, dental clinics were re-opened with all protective measures for the patients as well as the dental professionals and the clinic staff [5]. Clinics were also advised for having a triage section where the patients with the virus symptoms like fever, cold and dry cough would be asked to get themselves tested and seek medical help before entering the dental clinic. Even after a lot of restrictions and careful preventive measures, many professionals have been infected with the COVID-19 virus. Fear of getting this unknown virus into their body on one hand, and guilt for endangering their families and relatives from this highly transmissible agent, has developed a havoc of stress, anxiety and depression among the dental professionals. In light of these concerns, the cause for potential reduction in the quality of the treatment provided might be a result of psychological distress [6].

Specifically, peritraumatic distress reactions refer to behaviors, emotions, thoughts and symptoms associated with stress during or immediately after the traumatic event (e.g., fear of dying, fear of losing control, tachycardia, dissociative symptoms, dizziness, sweating, and others). Evidence suggests that peri-traumatic distress is a significant predictor for Post-Traumatic Stress Disorder (PTSD). It is believed that psychological stress is at its peak during the 1 st phase of pandemic. In a pandemic emergency, with the help of an easy, short and accurate instrument, measurement of peri-traumatic distress can be done.

In China, a large-scale nationwide survey of psychological distress was conducted during the COVID19 outbreak in the general population by Qiu et al. [7]. They developed a self-administered questionnaire named COVID-19 Peritraumatic Distress Index (CPDI). CPDI is considered a rapid online compilation tool, easy to understand and accepted by people. Items in the questionnaire inquired about the frequency of anxiety, depression, specific phobias, cognitive change, avoidance and compulsive behaviour, physical symptoms and loss of social functioning in the past week, with a range from 0 to 100.

The present study will gauge the current mental health burden on the dentists in Bhubaneswar, and therefore provide a solid basis for tailoring and implementing pertinent mental health intervention policies to confront this challenge in an efficient and effective manner. The objectives are to establish the validity of COVID-19 Peritraumatic Distress Index (CPDI) questionnaire among dental professionals in Bhubaneswar, India, and to assess the prevalence of peritraumatic distress and determine its relationship with associated factors during the COVID-19 pandemic outbreak among the dentists.

\section{Material and Methods}

Study Design and Sample 
An online cross-sectional survey was carried out for assessing psychological stress among 234 registered dentists practicing in Bhubaneswar representing Odisha state of India.

\section{Data Collection and Ethical Clearance}

Data collection was done from June-August 2020. The study was completely anonymous, with no disclosures of personal details. The ethical clearance was obtained from the institutional review board (Ref.No/DMR/IMSSH/SOA/180315 dated 27.05.2020). Informed consent was taken from all the participants prior to filling up of questionnaire. Only those who gave their consent for participation and the dentists practicing only in the city of Bhubaneswar were included.

Using an internet platform (www.googleforms.com), survey questions were prepared and by means of snowball technique, they were either mailed to or shared via an online platform like WhatsApp to 300 dental professionals. For returning the completed responses, one-week time was permissible from the day of sending the questionnaire to the individual participant, with one follow-up reminder message on the fourth day. The accomplished responses received were 242 (response rate $80.6 \%$ ), out of which eight incomplete questionnaires were rejected, which resulted in 234 valid forms for final analysis.

The initial part of the questionnaire included demographics like age, gender, type of practice (private, institutional, both) and years of experience. COVID-19 Peritraumatic Distress Index (CPDI) [7] with 24items was used to assess the peritraumatic distress. Its content refers to anxiety, depression, specific phobias, cognitive change, avoidance and compulsive behavior, physical symptoms and loss of social functioning in the past week. Further, they can be grouped under four domains (Negative mood, Changes in behaviour and cognitive skills, Tired and hyperactivated and Somatization) concerned with the COVID outbreak. All the items are rated on a 5-point scale ranging from 0 ('not at all') to 4 ('extremely'). The total score ranges from 0 to 100. A score below 28 indicates no distress, between 28 and 51 mild to moderate distress, and above 51 severe distress [7].

A couple of Psychiatrists from Sum Medical College and Hospital, Bhubaneswar, were approached to verify the content validity of CPDI to be used among dentists. Internal consistency of the questionnaire was ascertained by Cronbach's alpha score of 0.92 .

\section{Data Analysis}

The collected data was analyzed using a statistical package for social sciences (SPSS) software, version 20.0 (SPSS Inc., Chicago, IL, USA). The Kolmogorov Smirnov test revealed a non-normal distribution of data; hence, non-parametric tests were used to test the hypothesis. Descriptive statistics and Pearson's Chi-square test were used to check the association of all items in the questionnaire with respect to age, gender and education. A binomial logistic regression model was used to calculate odds ratios (OR) for factors independently associated with distress in the study sample. A linear regression model was used to predict which domain of the questionnaire contributed to maximum CPDI score.

\section{Results}

A total of 234 responses from dentists of Bhubaneswar were obtained via Google forms. The demographic details of the participants are listed in Table 1. Out of 234 participants, 70 (29.9\%) were males and $164(70.1 \%)$ were females, revealing a clear mainstream of the latter group. Two-thirds of the participants were aged below thirty years, with a mean age of $30.58 \pm 6.70$ years. By education, $99(42.3 \%)$ were BDS 
graduates, $127(54.3 \%)$ were MDS graduates and only about $8(3.4 \%)$ of the participants were pursuing their Ph.D. Half the participants $(50 \%)$ were associated with only institutions, while $33.3 \%$ had both private set up as well as the institutional attachment. A minor proportion (20.9\%) had more than 10 years' professional experience.

Table 1. Demographic details of the study participants.

\begin{tabular}{|c|c|}
\hline Variables & $\mathbf{N}(\%)$ \\
\hline \multicolumn{2}{|l|}{ Gender } \\
\hline Male & $70(29.9)$ \\
\hline Female & $164(70.1)$ \\
\hline \multicolumn{2}{|l|}{ Age Groups (In Years) } \\
\hline $21-25$ & $62(26.5)$ \\
\hline $26-30$ & $89(38.0)$ \\
\hline $31-35$ & $20(8.5)$ \\
\hline $36-40$ & $42(18.0)$ \\
\hline$>40$ & $21(9.0)$ \\
\hline \multicolumn{2}{|l|}{ Education } \\
\hline BDS & $99(42.3)$ \\
\hline MDS & $127(54.3)$ \\
\hline Ph.D & $8(3.4)$ \\
\hline \multicolumn{2}{|l|}{ Practice } \\
\hline Private & $39(16.7)$ \\
\hline Institutional & $117(50.0)$ \\
\hline Both & $78(33.3)$ \\
\hline \multicolumn{2}{|l|}{ Years of Experience } \\
\hline$<10$ & $185(79.1)$ \\
\hline$>10$ & $49(20.9)$ \\
\hline
\end{tabular}

Amongst the 24 questions, maximum stress was observed in the question asking, "I feel sympathetic to the COVID-19 patients and their families. I feel sad about them”, in the section of negative mood. About 83 $(35.5 \%)$ of the participants agreed on having an extreme level of stress regarding the same and this was found to be statistically significant in terms of gender $(p<0.001)$, education $(p<0.01)$ and age groups $(p<0.001)$. Similarly, minimum stress was reported in the question asking "I lost my appetite" in the section of somatization. This was found to be statistically significant among gender $(\mathrm{p}<0.002)$ (Table 2).

Table 2. Response of the study population to the COVID-19 Peritraumatic Distress Index questionnaire.

\begin{tabular}{|c|c|c|c|c|c|}
\hline Items & $\begin{array}{l}\text { Not at all } \\
\mathrm{N}(\%)\end{array}$ & $\begin{array}{l}\text { Less } \\
\mathrm{N}(\%)\end{array}$ & $\begin{array}{l}\text { Neutral } \\
\mathrm{N}(\%)\end{array}$ & $\begin{array}{l}\text { More } \\
\mathrm{N}(\%)\end{array}$ & $\begin{array}{c}\text { Extremely } \\
\text { N }(\%)\end{array}$ \\
\hline $\begin{array}{l}\text { 1. Compared to usual, I feel more nervous and } \\
\text { anxious. }\end{array}$ & $17(7.3)$ & $52(22.2)$ & $79(33.8)$ & $70(29.9)$ & $16(6.8)$ \\
\hline $\begin{array}{l}\text { 2. I feel insecure and bought a lot of masks, } \\
\text { medications, sanitizer, gloves and/or other home } \\
\text { supplies. }\end{array}$ & $28(12.0)$ & $64(27.4)$ & $66(28.2)$ & $49(20.9)$ & $27(11.5)$ \\
\hline $\begin{array}{l}\text { 3. I can't stop myself from imagining myself or my } \\
\text { family being infected and feel terrified and anxious } \\
\text { about it. }\end{array}$ & $32(13.7)$ & $48(20.5)$ & $57(24.4)$ & $63(26.9)$ & $34(14.5)$ \\
\hline 4. I feel empty and helpless no matter what I do. & $68(29.1)$ & $59(25.2)$ & $55(23.5)$ & $36(15.4)$ & $16(6.8)$ \\
\hline $\begin{array}{l}\text { 5. I feel sympathetic to the COVID- } 19 \text { patients and } \\
\text { their families. I feel sad about them. }\end{array}$ & $11(4.7)$ & $17(7.3)$ & $59(25.2)$ & $64(27.4)$ & $83(35.5)$ \\
\hline $\begin{array}{l}\text { 6. I feel helpless and angry about people around me, } \\
\text { governors, and media. }\end{array}$ & $48(20.5)$ & $52(22.2)$ & $75(32.1)$ & $39(16.7)$ & $20(8.5)$ \\
\hline 7. I am losing faith in the people around me. & $87(37.2)$ & $37(15.8)$ & $61(26.1)$ & $39(16.7)$ & $10(4.3)$ \\
\hline $\begin{array}{l}\text { 8. I collect information about COVID-19 all day. } \\
\text { Even if it's not necessary, I can't stop myself. }\end{array}$ & $75(32.1)$ & $73(31.2)$ & $41(17.5)$ & $19(8.1)$ & $26(11.1)$ \\
\hline
\end{tabular}


9. I will believe the COVID-19 information from all sources without any evaluation.

\begin{tabular}{lcccc}
$141(60.3)$ & $44(18.8)$ & $28(12.0)$ & $12(5.1)$ & $9(3.8)$ \\
$124(53.0)$ & $44(18.8)$ & $53(22.6)$ & $5(2.1)$ & $8(3.4)$ \\
$160(68.4)$ & $39(16.7)$ & $24(10.3)$ & $9(3.8)$ & $2(0.9)$ \\
$105(44.9)$ & $52(22.2)$ & $50(21.4)$ & $14(6.0)$ & $13(5.6)$ \\
$101(43.2)$ & $61(26.1)$ & $46(19.7)$ & $22(9.4)$ & $4(1.7)$ \\
$59(25.2)$ & $67(28.6)$ & $49(20.9)$ & $48(20.5)$ & $11(4.7)$ \\
$78(33.3)$ & $75(32.1)$ & $46(19.7)$ & $28(12.0)$ & $7(3.0)$ \\
$55(23.5)$ & $85(36.3)$ & $59(25.2)$ & $31(13.2)$ & $4(1.7)$ \\
$84(35.9)$ & $72(30.8)$ & $44(18.8)$ & $27(11.5)$ & $7(3.0)$ \\
$80(34.2)$ & $72(30.8)$ & $45(19.2)$ & $16(6.8)$ & $21(9.0)$ \\
$170(72.6)$ & $25(10.7)$ & $20(8.5)$ & $6(2.6)$ & $13(5.6)$ \\
$124(53.0)$ & $46(19.7)$ & $36(15.4)$ & $24(10.3)$ & $4(1.7)$ \\
$136(58.1)$ & $50(21.4)$ & $35(15.0)$ & $7(3.0)$ & $6(2.6)$ \\
$150(64.1)$ & $48(20.5)$ & $22(9.4)$ & $9(3.8)$ & $5(2.1)$ \\
$178(76.1)$ & $20(8.5)$ & $29(12.4)$ & $5(2.1)$ & $2(0.9)$ \\
$158(67.5)$ & $36(15.4)$ & $33(14.1)$ & $2(0.9)$ & $5(2.1)$ \\
\hline
\end{tabular}

Mean CPDI score was found to be $29.08 \pm 15.47$, which shows that the majority of the dentists had mild to moderate distress due to COVID pandemic. Nearly half $(47.9 \%)$ the study population showed distress, dispersed as mild to moderate $(39.3 \%)$ and severe $(8.6 \%)$ (Table 3$)$.

Table 3. Distribution of CPDI groups.

\begin{tabular}{lcc}
\multicolumn{2}{c}{ CPDI } & N (\%) \\
\hline No Distress & $122(52.1)$ \\
Mild to Moderate Distress & $92(39.3)$ \\
Severe & & $20(8.6)$ \\
\multicolumn{2}{c}{ Total } & $234(100.0)$ \\
\hline
\end{tabular}

The association of stress levels with demographic variables such as gender, age groups, education, practice and years of experience was analysed using the Chi square test. All the variables except the years of experience were found to be statistically significant $(\mathrm{p}<0.05)$ (Table 4$)$.

Table 4. Association of demographic characteristics with different levels of stress.

\begin{tabular}{|c|c|c|c|c|c|}
\hline & & & CPDI Groups & & \\
\hline & & $<28$ & $28-51$ & $>51$ & p-value \\
\hline Gender & & & & & \\
\hline Gender & Male & $45(64.3)$ & $22(31.4)$ & $3(4.3)$ & $0.03 *$ \\
\hline & Female & $77(47.0)$ & $70(42.7)$ & $17(10.4)$ & \\
\hline & Total & $122(52.1)$ & $92(39.3)$ & $20(8.6)$ & \\
\hline Age Groups & $<25$ Years & $38(61.3)$ & $22(35.5)$ & $2(3.2)$ & $0.003^{*}$ \\
\hline & 26-30 Years & $36(40.4)$ & $44(49.4)$ & $9(10.1)$ & \\
\hline & 31-35 Years & $9(45.0)$ & $8(40.0)$ & $3(15)$ & \\
\hline & 36-40 Years & $20(47.6)$ & $16(38.1)$ & $6(14.3)$ & \\
\hline & $>40$ Years & $19(90.5)$ & $2(9.5)$ & $\mathrm{O}(0.0)$ & \\
\hline Education & BDS & $50(50.5)$ & $43(43.4)$ & $6(6.1)$ & $0.04 *$ \\
\hline
\end{tabular}




\begin{tabular}{|c|c|c|c|c|c|}
\hline & MDS & $64(50.4)$ & $49(38.6)$ & $14(11.0)$ & \\
\hline \multirow{3}{*}{ Practice } & Ph.D & $8(100.0)$ & $\mathrm{o}(0.0)$ & o (0.0) & \\
\hline & Private & $22(56.4)$ & $17(43.6)$ & $\mathrm{O}(0.0)$ & $0.006^{*}$ \\
\hline & Institutional & $57(48.7)$ & $53(45.3)$ & $7(6.0)$ & \\
\hline \multirow{3}{*}{ Years of Experience } & Both & $43(55.1)$ & $22(28.2)$ & $13(16.7)$ & \\
\hline & $<10$ Years & $94(50.8)$ & $77(41.6)$ & $14(7.6)$ & 0.28 \\
\hline & $>10$ Years & $2(57.1)$ & $15(30.6)$ & $6(12.2)$ & \\
\hline
\end{tabular}

All the items in the questionnaire were grouped under four dimensions, such as; negative mood, change in behavior, tired and hyperactivated and Somatization. Maximum contribution towards stress was through negative mood with a mean score of $10.35 \pm 4.42$, following the section of change in behaviour and cognitive skills $(8.29 \pm 5.89)$, tired and hyperactivated $(8.02 \pm 5.96)$ and somatization $(3.16 \pm 3.74)($ Table 5$)$. About $99 \%$ of the variance could be explained by the linear regression model. A statistically significant difference $(\mathrm{p}=0.001)$ was found in all the dimensions, with the highest influence recorded from tired and hyperactivated $(\beta=0.39)$, followed by a change in behaviour and cognitive skills $(\beta=0.31)$, negative mood $(\beta=0.30)$ and somatization $(\beta=0.24)$.

Table 5. Linear regression used among the four main domains of CPDI.

\begin{tabular}{|c|c|c|c|c|c|}
\hline Domains & Mean & Std. Deviation & Adjusted $\mathrm{R}^{2}$ & Beta Coefficient & p-value \\
\hline Negative Mood & 10.35 & 4.423 & 0.998 & 0.301 & 0.001 \\
\hline Change in Behavior & 8.29 & 5.890 & & 0.312 & 0.001 \\
\hline Tired and Hyperactivated & 8.02 & 5.965 & & 0.399 & 0.001 \\
\hline Somatization & 3.16 & 3.747 & & 0.245 & 0.001 \\
\hline
\end{tabular}

For assessment of risk, a significant stress group was formed combining mild to moderate and severe stress groups. Binomial logistic regression was then used to find out the predictor causing significant stress in dental professionals. The resultant model showed a good fit with Hosmer and Lemeshow test $(p=0.86)$ and the Nagelkerke (pseudo) $\mathrm{R}^{2}$ was 0.20. It was found that, in comparison to no or low stress, the odds of having significant stress increased among females $(\mathrm{OR}=2.01, \mathrm{p}=0.04)$, which was statistically significant. In relation to age, the stress was observed to me more with the younger age group. This was pronounced in the 26-30 years $(\mathrm{OR}=2.292, \mathrm{p}=0.003)$ and 31-35 years group $(\mathrm{OR}=2.113, \mathrm{p}=0.01)$. In comparison to dentists having both private and institutional practice, the private practitioners had higher odds $(\mathrm{OR}=1.09, \mathrm{p}=0.85)$ and those attached to institution had lower stress $(\mathrm{OR}=0.69, \mathrm{p}=0.30)$ and the results were non-significant. In contrast to education, dentists with MDS degree had more stress $(\mathrm{OR}=1.996, \mathrm{p}=0.05)$, which was statistically significant (Table 6).

Table 6. Binomial logistic regression to assess stressor with No or Less Stress as a Comparison group to those with Significant Stress (Mild to Moderate and Severe).

\begin{tabular}{|c|c|c|c|}
\hline Variables & Odds Ratio & 95\% Confidence Interval & p-value \\
\hline \multicolumn{4}{|l|}{ Gender } \\
\hline Females & 2.01 & $1.03-3.94$ & $0.04^{*}$ \\
\hline \multicolumn{4}{|l|}{ Males $^{\mathrm{a}}$} \\
\hline \multicolumn{4}{|l|}{ Age Groups (in Years) } \\
\hline $20-25$ & 1.965 & $1.049-3.442$ & $0.02 *$ \\
\hline $26-30$ & 2.292 & $1.319-4.440$ & $0.003^{*}$ \\
\hline $31-35$ & 2.113 & $1.202-4.126$ & $0.01 *$ \\
\hline $36-40$ & 1.383 & $1.005-2.968$ & $0.004^{*}$ \\
\hline$>40^{\mathrm{a}}$ & & & \\
\hline
\end{tabular}

Education 


\begin{tabular}{|c|c|c|c|}
\hline BDS & 1.623 & $0.618-2.814$ & 0.32 \\
\hline MDS & 1.996 & $1.018-3.324$ & $0.05^{*}$ \\
\hline \multicolumn{4}{|l|}{$\mathrm{PhD}^{\mathrm{a}}$} \\
\hline \multicolumn{4}{|l|}{ Practice } \\
\hline Private & 1.09 & $0.42-2.84$ & 0.85 \\
\hline Institutional & 0.69 & $0.33-1.41$ & 0.30 \\
\hline Both $^{\mathrm{a}}$ & & & \\
\hline
\end{tabular}

a: Constant; *Significance.

\section{Discussion}

The dental profession is one of the most vulnerable groups owing to aerosol emission. Hence, we focussed primarily on dentists' psychological conditions during the COVID-19 pandemic. The level of peritraumatic stress in the current study was evaluated using CPDI after its validation (Cronbach's alpha $=0.92$ ). This was similar to the Italian validation of the CPDI (Cronbach's alpha= 0.92), which is indicative of CPDI as a valid tool to measure stress during COVID-19 among any population [8].

The mean CPDI score in our population was $29.08 \pm 15.47$. Our results were slightly higher than Indian (20.66 \pm 12.03$)$ [9], Chinese $(23.65 \pm 15.45)[7]$ and Italian (24.96 \pm 16.66$)[8]$ populations. A comparatively higher mean CPDI score was reported among the Iranian (34.54 \pm 4.92$)$ population [10]. This regional difference between Indian populations (Tamilnadu and Odisha) may be attributed to the timing of data collection, as Odisha had already become an epicenter of the outbreak. Data collection completed during the lockdown and also the difference in study population may have contributed to high stress among dentists because of the risk associated with the exposure to patients.

In the current study, females compared to males had comparatively higher mild to moderate stress (42.7\% vs. $31.4 \%)$ and severe stress (10.4\% vs. 4.3\%). This was consistent with the findings of Prasad et al. [11] and the Italian sample where the difference in the percentages of distress between females and males was $24.61 \%$ and $14.6 \%$ for mild/moderate stress and $6.81 \%$ and $2.19 \%$ for severe stress, respectively [8]. We can emanate this fact with the ones already reported in the literature as well as amongst the Chinese sample, which reveals women as the group more vulnerable to stress and post-stress symptoms over time [7,12].

In our research, about $61.9 \%$ of dentists were anxious and terrified (less/ more/ extreme) from imagining them or their family being infected with COVID-19. However, in the study by Ahmed et al., almost $90 \%$ of the dentists were terrified and anxious about the same [13]. The later research covered dentists from around the world and was conducted in the initial outbreak of the pandemic leading to the variation in results. The difference in the type of questionnaire used can also be declared as the reason. Among all the questions used in CPDI questionnaire, extreme response (35.5\%) was observed in the question "I feel sympathetic to the COVID-19 patients and their families. I feel sad about them". A majority of females (37.2\%) and BDS graduates $(38.4 \%)$ responded extreme feelings about the same and it was statistically significant $(\mathrm{p}<0.05)$. Nonetheless, no significance ( $\mathrm{p}>0.05$ ) was seen concerning age groups.

The dentists belonging to the middle age group (31-35years) and with MDS degree were reported to have significantly major exposure to stress in comparison to other age groups $(\mathrm{p}<0.003)$ and education $(\mathrm{p}<0.01)$, respectively. It may be due to higher self-awareness about the disease impact and heightened spread [14]. Specialists who are more likely to handle stress than others may suffer from higher stress due to any negative life event, self-perception or coping style [15].

Nearly one-third of the population could not sleep well due to the stress of being infected. These results resonate with the study by Chakraborty and Chatterjee [16] and Roy et al. [17]. Dentists with $>10$ 
years of experience had severe and non-significant stress in our study. This was contrary to the findings of Mishra et al., where dentists with $<10$ years of experience had a significantly higher mean PSS (Perceived Stress Scale) [18]. The reason can be due to the difference in the index used for the measurement of stress. About $60 \%$ of the dentists felt insecure and bought a lot of masks, sanitizers and gloves. This was in accordance with the one reported by Roy et al., where $72 \%$ felt the need for the same [17].

In the present study, the predictors for higher stress in dentists were gender, age and education. This was similar to the research done by Zhang et al. [19] but contrary to the survey done in the Iranian population [10]. Our findings suggest that the predictors of stress vary within various countries. At the same time, gender can be seen as a constant predictor for stress among all three studies [8,10,19]. The variation in predictors can be owed to the different medical systems, lockdown policies, spread of information through various news platforms and social media, as well as isolation and quarantine effects.

Pandemics are often influential towards people's behavior in the community and create fear and anxiety [20-22]. Irrational decisions and poor treatment outcomes are certain side effects of mental stress, fear and anxiety, faced by healthcare professionals and dentists [23,24]. Hence, this study was an attempt to evaluate the mental health status of Indian dentists.

CPDI, a validated tool for measuring COVID-related psychological stress, is probably the first of its kind to be used among Indian dentists. The limitations of this study were that the samples were restricted to the dental professionals in the city of Bhubaneswar only. So, it cannot be generalized to the whole dentist population. Further research needs to be focused on other predictors of mental health during COVID time, identifying susceptible individuals, and implementing certain strategies to combat mental health issues.

\section{Conclusion}

Almost all spheres of human life have been affected with significant stress due to the COVID-19 pandemic. The findings of mild to moderate stress owing to the containment effort by Government and the related interpreters among dental professionals draw the attention of policymakers to plan appropriate strategies for early interventions as it is associated with negative outcomes on health and likewise influences daily activities.

\section{Authors' Contributions}

\begin{tabular}{|c|c|c|}
\hline $\mathrm{RN}$ & (D) https://orcid.org/0000-0002-0253-7720 & $\begin{array}{l}\text { Conceptualization, Methodology, Formal Analysis, Data Curation, Writing - Review and Editing } \\
\text { and Visualization. }\end{array}$ \\
\hline IM & https://orcid.org/0000-0002-0120-289X & $\begin{array}{l}\text { Conceptualization, Methodology, Validation, Formal Analysis, InvestigationData Curation and } \\
\text { Writing - Original Draft. }\end{array}$ \\
\hline DS & https://orcid.org/0000-0002-4969-5830 & Investigation, Writing - Review and Editing and Visualization. \\
\hline SM & https://orcid.org/0000-0001-6316-7500 & $\begin{array}{l}\text { Methodology, Investigation, Writing - Original Draft, Writing - Review and Editing and } \\
\text { Visualization. }\end{array}$ \\
\hline
\end{tabular}

\section{Financial Support}

None.

\section{Conflict of Interest}

The authors declare no conflicts of interest.

\section{Data Availability}

The data used to support the findings of this study can be made available upon request to the corresponding author. 


\section{Acknowledgments}

Authors would like to acknowledge all the study participants for their kind cooperation and participation in the study

\section{References}

[1] World Health Organization. Coronavirus disease (COVID-19) Pandemic. Available from: https://www.who.int/emergencies/diseases/novel-coronavirus-2019. [Accessed on November 23, 2020].

[2] Worlometer. India Corona virus cases. 2020. Available

from: https://www.worldometers.info/coronavirus/country/india/. [Accessed on December 27, 2020].

[3] Lu CW, Liu XF, Jia ZF. 2019-NCoV Transmission through the ocular surface must not be ignored. Lancet 2020; 395(10224):e39. https://doi.org/10.1016/So140-6736(20)30313-5

[4] Peng X, Xu X, Li Y, ChengL, Zhou X, Ren B. Transmission routes of 2019-NCoV and controls in dental practice. Int J Oral Sci 2020; 12(1):9. https://doi.org/10.1038/s41368-020-0075-9

[5] Dental Council of India. Dental Clinics Protocol, Dental Council of India. Available from: https://www.dciindia.gov.in/Admin/NewsArchives/Dental\%20Clinics\%20Protocols\%20Final.pdf. [Accessed on November 23, 2020].

[6] Remen RN. Recapturing the soul of medicine. West J Med 2001; 174:4-5. https://doi.org/10.1136/ewjm.174.1.4

[7] Qiu J, Shen B, Zhao M, Wang Z, Xie B, Xu Y. A nationwide survey of psychological distress among Chinese people in the COVID-19 epidemic: implications and policy recommendations. Gen Psychiatr 2020; $33(2)$ :e100213. https://doi.org/10.1136/gpsych-2020-100213

[8] Costantini A, Mazzotti E. Italian validation of CoViD-19 Peritraumatic Distress Index and preliminary data in a sample of general population. Riv Psichiatr 2020; 55(3):145-51. https://doi.org/10.1708/3382.33570

[9] Ramasubramanian V, Mohandoss AA, Rajendhiran G, Pandian PRS, Ramasubramanian C. Statewide survey of psychological distress among people of Tamil Nadu in the COVID-19 pandemic. Indian J Psychol Med 2020; 42(4):368-73. https://doi.org/10.1177/0253717620935581

[10] Jahanshahia AA, Dinanib MM, Madavanic AN, Li J, Zhang SX. The distress of Iranian adults during the Covid-19 pandemic - More distressed than the Chinese and with different predictors. Brain Behav Immun 2020; 87:124-5. https://doi.org/10.1016/j.bbi.2020.04.081

[11] Prasad M, Patthi BR, Singla A, Gupta R, Kumar JK, Dhama K, et al. Assessment of anxiety and depression among dental practitioners: an exploratory cross-sectional study. J Clin Diagn Res 2017; 11(10):ZCo1-ZCo4. https://doi.org/10.7860/JCDR/2017/26783.10701

[12] Sareen J, Erickson J, Medved MI, Asmundson GJG, Enns MW, Stein M, et al. Risk factors for post injury mental health problems. Depress Anxiety 2013; 30(4):32 1-7. https://doi.org/10.1002/da.22077

[13] Ahmed MA, Jouhar R, Ahmed N, Adnan S, Aftab M, Zafar MS, et al. Fear and practice modifications among dentists to combat novel Coronavirus disease (COVID-19) outbreak. Int J Environ Res Public Health 2020 ; 17(8):2821. https://doi.org/10.3390/ijerph17082821

[14] Roberts T, Miguel Esponda G, Krupchanka D, Shidhaye R. Factors associated with health service utilisation for common mental disorders: a systematic review. BMC Psychiatry 2018; 18:262.

https://doi.org/10.1186/s 12888-018-1837-1

[15] Nayak AS, Parkar SR, Nachane HB, Sangoi BA, Shinde RG. Gender variability of perceived stress and negative inferential feedback in depression. Indian J Psychol Med 2019; 41(4):331-7. https://doi.org/10.4103/IJPSYM.IJPSYM_343_18

[16] Chakraborty K, Chatterjee M. Psychological impact of COVID-19 pandemic on general population in West Bengal: A $\begin{array}{lllll}\text { cross-sectional study. } & \text { Indian } & \text { 2020; }\end{array}$ https://doi.org/10.4103/psychiatry.IndianJPsychiatry_276_20

[17] Roy D, Tripathy S, Kar SK, Sharma N, Verma SK, Kaushal V. Study of knowledge, attitude, anxiety and perceived mental health care need in Indian population during COVID-19 pandemic. Asian J Psychiatr 2020; 51:102083. https://doi.org/10.1016/j.ajp.2020.102083

[18] Mishra S, Singh S, Tiwari V, Vanza B, Khare N, Bharadwaj P. Assessment of level of perceived stress and sources of stress among dental professionals before and during the COVID-19 outbreak. J Int Soc Prevent Community Dent 2020; 10(6):794-802. https://doi.org/10.4103/jispcd.JISPCD_340_20

[19] Zhang SX, Wang Y, Rauch A, Wei F. Unprecedented disruption of lives and work: Health, distress and life satisfaction of working adults in China one month into the COVID-19 outbreak. Psychiatry Res 2020; $288: 112958$. https://doi.org/10.1016/j.psychres.2020.112958

[20] Gonzalez-Diaz JM, Lozano-Lesmes L, Campo-Arias A. Comment on "Mental health: why it still matters in the midst of a pandemic.” Braz J Psychiatry 2020; 42(4):451. https://doi.org/10.1590/1516-4446-2020-1042

[21] Silva DAR, Pimentel RFW, Merces MC. Covid-19 and the pandemic of fear: reflections on mental health. Rev Saude Publica 2020; 54:46. https://doi.org/10.11606/s1518-8787.2020054002486

[22] Talevi, D, Socci V, Carai M, Carnaghi G, Faleri S, Trebbi E, et al. Mental health outcomes of the COVID-19 pandemic. Riv Psichiatr 2020; 55(3):137-44. https://doi.org/10.1708/3382.33569 
[23] El-Hage, W, Hingray C, Lemogne C, Yrondi A, Brunault P, Bienvenu T, et al. Health professionals facing the coronavirus disease 2019 (COVID-19) pandemic: What are the mental health risks?. Encephale 2020; 46(3S):S73-S80. https://doi.org/10.1016/j.encep.2020.04.008.

[24] García-Fernández L, RomeroFerreiro V, López-Roldán PD, Padilla S, CaleroSierra I, Monzó-García M, et al. Mental health impact of COVID-19 pandemic on Spanish healthcare workers. Psychol Med 2020; 1-3. https://doi.org/10.1017/S0033291720002019 